\title{
ERJ
}

Engineering Research Journal

Faculty of Engineering

Menoufia University

\section{Assessment of the Surface Roughness and the Delamination in Drilling Hole of $\mathrm{Al} / \mathrm{SiCp} \mathrm{MMCs}$}

\author{
Abeer S. Eisa \\ Lecture, Production Engineering \& Mech. Design Dept., \\ Faculty of Engineering, Menoufiya University, Egypt. \\ Drabeereisa78@yahoo.com
}

\begin{abstract}
:
In this research, the analysis of the experimental results has been carried out to study the influence of the following input process parameters; three of the cutting speeds, five of the feed rates and five of the drill tools (HSS - different point angles-same diameter) on the process responses, i.e. the delamination factor ( $\mathrm{df}$ ) and the surface roughness ( $\mathrm{Ra})$ of the drilled hole. The drilling has been carried out on the plate of AL/SiCp MMC, with using three of volume fraction ratios. The results indicated that the delamination factor ( $\mathrm{df}$ ) is increased with the increase of; the feed rate, the tool point angle, the cutting speed and with the increase of volume fraction ratios. In addition, the surface roughness ( $\mathrm{Ra}$ ) of the drilled hole is increased with the increase of; the feed rate, the tool point angle and with the increase of volume fraction ratios, but decreases with the increase of the cutting speed.

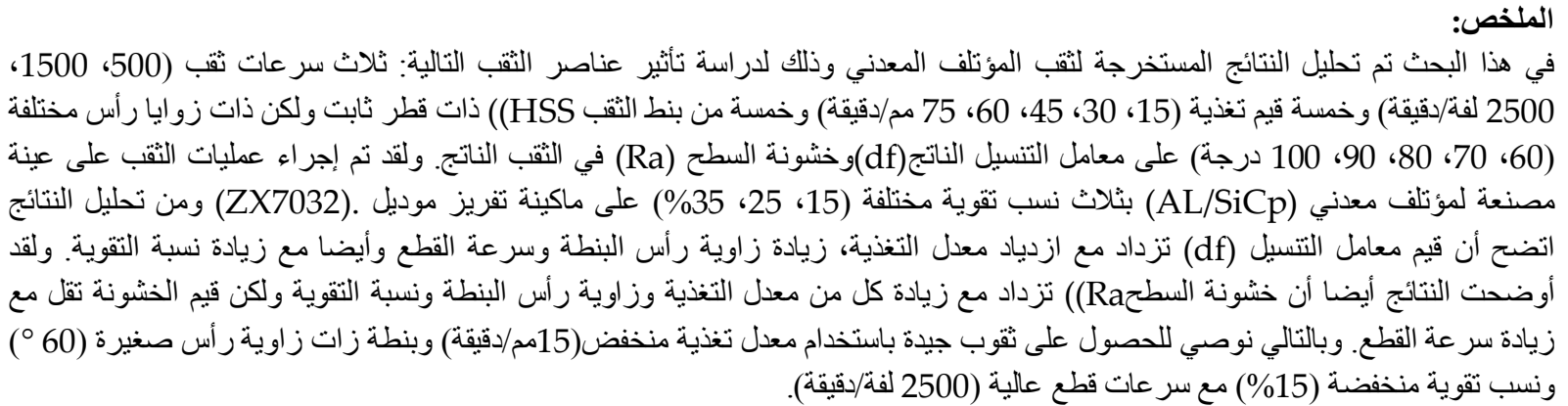

Keywords: Metal-matrix composites, Defects, Surface Quality, Surface Delamination, Drilling.

\section{Introduction}

Particulate metal matrix composites (PMMCs) have found wide applications in numerous industrial fields in which the parts are required to be light and heat resistant or wear resistant. Particularly, noncontinuously reinforced materials such as aluminum matrix composites reinforced by silicon carbide particles have become practical engineering materials. It is apparent that drilling of composite materials is a difficult task due to its heterogeneity and the number of problems, such as surface defects, particles pullout associated with the characteristics of the material and the cutting parameters that appear during the machining process. The surface roughness has a great influence on the functional properties of the product and the components surface roughness plays a vital role when these parts are assembled. The friction, the wear and the power transmission depend on material surface and contact environment. In addition, objective consideration may be with respect to a stress condition, precision fits, smooth motion...etc. Finding the rules that how process factors and environmental factors affect the values of the surface roughness will help to set the process parameters of the future and then improve production quality.

S. Senthil Babu, B. K. Vinayagam [1], presents the analysis of various parameters in drilling of $\mathrm{Al} / \mathrm{Sic}$ metal matrix composites and $\mathrm{Al} / \mathrm{Sic} / \mathrm{Gr}$ hybrid composites. The specimens (square slabs) are fabricated by stir casting method which has these dimensions $(100 \times 100 \times 10 \mathrm{~mm})$ and subsequently 
drilled using CNC vertical machining center with Carbide tipped tool. Taguchi's techniques with L27 orthogonal arrays is used. To correlate various parameters with surface roughness and thrust force, a model is established using response surface methodology. Numerous of the effective parameters are determined using analysis of variance. In the research of S. T. Huang, et al. [2], high-volumefraction of $\mathrm{SiCp} / \mathrm{Al}$ composites is used because this kind of composites has excellent thermo-physical properties. The effects of the cutting speed and feed rate on the drilling performance of $\mathrm{SiCp} / \mathrm{Al}$ composites with $56 \%$ of Sic particles are investigated experimentally. The drilling forces, the tool wear, and the surface quality of drilled-hole are studied and determined. From the results, it is obvious that the feed rate is one of the main cutting parameters that affect the drilling performance but cutting speed has no significant effect on the thrust force. The analysis and optimization of drilling parameters for the tool wear and hole dimensional accuracy of B4C reinforced Al-alloy is presented in the work of A. Taskesen, K. Kutukde [3]. The drilling parameters, which evaluated and optimized are tool wear and size error of drilled hole by used multiple performance characteristics and Taguchi's L27, 3level, 4-factor orthogonal array for the different tests. Abrasive wear and built up edge (BUE) formation are seen in the tool wear, and the corner wear is of major importance. From the experimental results, the tool wear increased with the particle mass fraction and decreased with the feed rate. The particle mass fraction, followed by feed rate, drill hardness and spindle speed have a major effect on the flank wear of the cutting tool. Cutting speed had less effect on the tool wear than the other drilling parameters over the used range of speeds. Higher BUE formation is observed with HSS tools than TiAlN coated carbide tools but uncoated tools are subjected to greater BUE than the coated drills. Moreover, the produced hole sizes are negatively affected by the tool wear, and the best results are obtained with coated carbide drills. Also, TiAlN coated carbide drills showed the best performance with regard to the tool wear as well as hole size and these results are estimated by using Grey relational analysis. The largest grey relational grade is found for the B4C particle content of $10 \%$, and the feed rate of $0.3 \mathrm{~mm} / \mathrm{rev}$, the spindle speed of
$1500 \mathrm{rpm}$ and the drill material of TiAlN coated carbide. These values are the recommended levels of the drilling parameters when the minimization of the tool wear and Diametral error are simultaneously considered. In addition, the optimal combination of the drilling parameters could be used to obtain both minimum tool wear and Diametral error. In the work of, Vikas K Doomra, et al. [4], a finite element model has been developed using finite element platform (ABAQUS/Explicit) to simulate the drilling behavior of Al1100/10 \% Sic metal matrix composite. The influence of the two cutting parameters, the cutting speed and the feed rate on the thrust force are studied experimentally. The results indicated that the thrust force experimentally increases with an increase in the cutting speed and the feed rate. Low both cutting speed and the feed rate should be preferred while drilling Al1100/10 \% Sic MMCs. A three-dimensional FE model has been proposed to predict the thrust force during drilling of MMCs and the predicted results have been compared with experimental results. The magnitude of thrust force obtained from the proposed finite element model is in close agreement with the experimental values. The proposed finite element model is quite efficient to predict the thrust force signals generated during drilling of metal matrix composites. The research of, Sarbjit Singh [5], studied the effect of change in drill point geometry on the drilling quality characteristics of the drilled hole wall for Al-6063/10\% Sic MMC using Taguchi design of experiments. The used drilling parameters are specific cutting pressure and surface roughness of the drilled hole wall. The levels of the used process parameters are established by Taguchi's methodology for optimum values of the output responses. The analysis of the chip formation reveals the cutting mechanism of the primary and the secondary cutting edge of modified drill point geometry is conducted. Single conical chips produced in the case of primary cutting edge and single ring type of chips produced in the secondary cutting edge respectively. During drilling with the modified drill geometry, no burr formation observed either at the entrance or at the exit side. Therefore, no additional machining operation needed, and the overall cost of production is reducing. The main factor, which influences the specific cutting pressure, is the step diameter followed by feed rate and tool point angle. 
A large lump of material has been sheared off from cutting zone by the cutting edge at higher feed rate. Therefore, an increase in the energy transferred from drill point geometry to the workpiece material being sheared and causes an increase in the thrust force and torque values. The burnishing and honing effect produced by the Sic particulates has a vital role in the behavior of surface roughness with respect to process parameters. The difference in the values of cutting forces increases the temperature at the cutting zone and facilitates stable Built up edge (BUE) formation. The burnishing effect produced by entrapped abrasive particles leading to an improvement in the surface finish of the drilled hole wall. The assessment of the thrust force and surface roughness in the drilling of $\mathrm{Al} / 15 \% \mathrm{Sic} / 4 \%$ Graphite hybrid metal matrix composite is presented by A. Muniaraj, et al. [6]. This composite is fabricated using stir casting method. The experiments plan is prepared to study the effect of spindle speed and feed rate on the thrust force and surface roughness using coated carbide twist drill and carbide multifaceted drills of $4 \mathrm{~mm}$ diameter under various cutting conditions. From the results, the coated carbide tool performs better than multifaceted carbide drill in term of improved surface finish of the drilled hole. The micro cracks, the particle pulls out and the shearing of particles are shown in the drilled surface. The feed rate is the main factor, which influences on the thrust force and drilled surface. The increase in the feed rate led to an increase in the surface roughness values and decreases with the increase in the spindle speed. For all cutting conditions, coated carbide tool exhibits higher thrust force when compared with multifaceted carbide drill. In the work of Srinivasan, et al. [7], an attempt has been made to model the machinability evaluation through the response surface methodology in the machining of homogenized 10\%micron A12O3 LM25 Al MMC manufactured through stir casting method. The combined effects of three machining parameters including the cutting speed, the feed rate and the depth of cut based on three performance characteristics of the tool wear, the surface roughness ( $\mathrm{Ra}$ ) and the cutting force are investigated. These parameters are optimized using desirability-based approach response surface methodology. The developed model used for predicting tool life, surface roughness and cutting force. The optimizing of process parameters gives lower surface finish and cutting force. The surface roughness is better with the increase of the cutting speed whilst increasing feed adversely affects the surface roughness. From the results, cutting speed has the most dominant effect on the tool wear and the cutting force almost linearly varies with feed rate. The cutting force is higher at low cutting speed and the interactions of cutting speed with feed rate and depth of cut dominantly affect the cutting forces. The established model has been validated experimentally and exhibits low values of error. R.Venkatesh A., et al. [8], presented a work to overcome the problem of poor machinability of Aluminum Silicon Carbide (A356-Sic) materials. Aluminum A356 is the base matrix material reinforced with $20 \%$ weight by volume of Silicon Carbide particles of mean diameter $55 \mu \mathrm{m}$ to $80 \mu \mathrm{m}$ is used. Minimum power consumed by the main spindle, less surface roughness and minimum tool wear are the major parameters which be investigated. Due to the constancy of the tool at higher cutting speed and easy removal of material, the surface finish is better at this stage. The (PCD) tool of grade 1300 performs well in metal removal rate, but wear is more. The use of low feed rate $(0.108$ $\mathrm{mm} / \mathrm{rev}$ ) has resulted from a decrease in cutting force and when using high feed rate of $(0.368 \mathrm{~mm} / \mathrm{rev})$ with high depth of cut has resulted from the good amount of metal removal. The increase in the cutting speed improves surface finish, and as the feed rate increases, surface finish improves only up to a certain level after that it starts deteriorates. A. Muniaraj, et al. [9] presented work on the influence of drilling parameters on thrust force when drilling of Sic and graphite reinforced aluminum matrix composites by step drill. The experiments of this work are conducted to study the effect of the spindle speeds (1000, 2000 and $3000 \mathrm{rpm})$, the feed rates $(0.05,0.10$ and $0.15 \mathrm{~mm} / \mathrm{rev}$ ) and different diameter of drills (4, 8 and $12 \mathrm{~mm}$ ) with dry drilling and TiN coated solid carbide step drills. To study the influence of machining parameters on drilling of hybrid metal matrix composites, computer numerical control machining center is used. From the experimental results, the feed rate is the main factor that influences the thrust force and affects drilling forces but cutting speed has not much effect over the range of spindle speeds. The increase in the cutting speed is led to 
decreases in thrust the forces. The coating material of the used tool is removed due to the abrasive action of the Sic particles. Vijaykumar Hire math, et al. [10], presented a study on the machinability aspects of B4Cp reinforced $6061 \mathrm{Al}$ alloy with $37 \mu \mathrm{m}$ and $88 \mu \mathrm{m}$ particulates produced by stir casting method. To recognize morphology and distribution of $\mathrm{B} 4 \mathrm{C}$ particles in the matrix of $6061 \mathrm{Al}$, the composite is prepared using Scanning Electron Microscopy equipped with EDX analysis (Hitachi Su-1500 model). Using a (PCD) tool to study the effect of particle size on the cutting forces and the surface roughness under varying cutting parameters viz. two of cutting speed, feed rate and depth of cut. From the analysis of the results, good uniform distribution of $\mathrm{B} 4 \mathrm{C}$ particulates in the $6061 \mathrm{Al}$ matrix is achieved due to the addition of K2TiF6 halide salt. The surface roughness of the composite influenced by cutting speed and surface roughness is high with $88 \mu \mathrm{m}$ particle reinforced composites and when the particle size increases surface roughness also increased. Sarbjit Singh, et al. [11] presented work on the optimization of the process parameters for drilling of (MMC) using Taguchi techniques. The targets of the present investigations are to study the effect of drilling parameters (cutting speed, feed rate and the drill point geometry) on the output responses such as thrust force, specific cutting pressure and surface roughness. The technique of Taguchi applied to obtain an optimal setting for drilling process parameters for optimizing the output quality characteristics. The results indicated that the effect of cutting speed on the thrust force shows a quadratic behavior, it increases with an increase in cutting speed and then decreases. In addition, the thrust force is varying with different drill point geometry and the Jo-drill point shows a minimum value of thrust force. The specific cutting pressure increased with the increase in the cutting speed and decreases with the increase in feed rate. The precipitous decrease in specific cutting pressure shows when used Jo-drill point than four facet and parabolic drill point geometry. The contribution percentage of the drilling parameters while predicting specific cutting pressure is, cutting speed (Insignificant), feed rate $(53 \%)$ and drill point geometry (38\%). The surface roughness decreases at upper cutting speed due to the honing effect produced by the entrapped abrasive particles. The contribution percentages of the drilling parameters while predicting surface roughness are, cutting speed $(16 \%)$, feed rate $(31 \%)$ and drill point geometry $(47 \%)$. The influence of cutting parameters on the thrust force, the surface roughness and burr height during drilling of the pure base alloy (Al2219), mono composite (Al- 2219+8\%B4C) and hybrid composite (Al-2219+8\%B4C+3\%Gr) MMCs is investigated in the work of, V M Rabindranath,et al. [12]. The drilling process is conducted on CNC machine with TiN coated HSS tool, M42 (Cobalt grade) and carbide tools at various spindle speeds and feed rates. From the results, the feed rate has more influence on the thrust force and the surface roughness. The fewer values of the thrust force and the discontinuous chips produced during drilling of hybrid composites when compared with mono and base alloy during the process. It is may be due to the solid lubricant property of graphite which reduces the thrust force, burr height and lower surface roughness. The better surface finish obtained with Carbide tool at low feed rate and high spindle speeds compared to the other two types of cutting tool materials. The surface roughness increased with the increase of the feed rate and decreases with the increase of the cutting speed. It is clear that, when machining hybrid composites, a poor surface finish obtained due to graphite particle pull out from the drilled surface. When compared the height of exit burr for different types of drill tools, it is less during drilling Graphitic composites. The chip formed of hybrid composites are of discontinuous type, and it is easier for chip disposal. In the research of $\mathrm{T}$. Rajmohan, K. Palanikumar [13], the modeling and analysis of machining responses such as the thrust force, the surface roughness, the burr height, and the tool wear in the drilling of Al 356 aluminum alloy reinforced with silicon carbide of size $25 \mu \mathrm{m}$ and mica of size $45 \mu \mathrm{m}$ using carbide, coated carbide, and polycrystalline diamond drills is presented. The chosen of numerical factors are, spindle speed, feed rate, and weight percent of silicon carbide and the drill material is considered as the categorical factor. D-optimal design based on the response surface methodology employed to carry out the experimental study. From the analysis of the results, the predicted values through the developed model are well in agreement with the experimental results. In addition, 
the feed rate is the highly influential parameter that influences the thrust force, surface roughness, tool wear, and burr height (exit) in the drilling of hybrid metal matrix composites. PCD drilling tool performs better than the other used tools in terms of improved surface finish and reduced thrust force, tool wear, and burr height in the drilling of composites. The increase in both of the feed rate and the spindle speed increases the tool wear and vice versa. ANOVA results indicated that the experimental data are well correlated with the predicted results at a $95 \%$ confidence interval. Therefore, the used technique can be very useful for a reliable prediction of different performances. Hari Singh, et al. [14], presented work on Multi-Response Optimization in drilling of Al6063/Sic/15\% MMC. The output response is the surface roughness, the burr height and the error in hole diameter under the experimental conditions of the cutting speed, the feed rate, the step angle, and the cutting environment. By using L27 orthogonal array, the drilling experiments conducted on these composites using high-speed steel step drill bits. A combination of three techniques (orthogonal array, design of experiments and grey relational analysis) are ascertained best possible drilling process parameters that give minimum surface roughness, burr height and the error in hole diameter. The optimal levels of process parameters are the cutting speed of $150.72 \mathrm{~m} / \mathrm{min}$, the feed rate of $0.05 \mathrm{~mm} / \mathrm{rev}$, the step angle of $90^{\circ}$ and the cutting environment of water-soluble oil. The results, when used the Analysis of Variance Method, indicated that feed rate has maximum influence $(60.59 \%)$ followed by step angle $(19.07 \%)$ and cutting speed $(11.48 \%)$ in affecting the drilling of composites and the interaction of cutting speed and feed is found be significant (4.98\%). Ahmad Mayyas, et al. [15], present the modeling of the drilling process for aluminum composites using Multiple Regression Analysis and Artificial Neural Networks. The modeling of the machinability of selflubricated aluminum /alumina/graphite hybrid composites synthesized by the powder metallurgy method investigated in this work. Multiple regression analysis (MRA) and artificial neural networks (ANN) used to investigate the influence of some parameters on the thrust force and torque in the drilling processes of self-lubricated hybrid composite materials. The two methods, which used in prediction, showed that $\mathrm{Al} 2 \mathrm{O} 3$, Gr and cutting feed (f) are the most significant parameters on the drilling process, while spindle speed seemed insignificant. Modeling methods revealed that reinforcement fractions are the important factors that influence the responses (i.e. thrust force and torque) followed by the feed rate. The used ANN models showed a close matching between the model outputs and the measured outputs, and the values of the mean absolute relative errors are $(2.89 \%)$ thrust force models, $(0.82 \%)$ for torque while MRA model error values are $(7.10 \%)$ and $(12.59 \%)$, respectively. From the deep analysis, the models can be used efficiently for prediction potentials for non-experimental patterns which, in turn, save experimental time and cost and the ANN methodology consumes less time and gives higher accuracy.

From the deep study of the previous literature review, this field needs more researches and studies to understand and analyze the behavior of various defects especially the surface roughness and delamination with different cutting parameters and different conditions of drilling accurately. During machining of MMCs, many factors affect the surface roughness and delamination in the drilled hole. Feed rate and cutting speed are the important factors that affect the quality of the drilled hole. Volume fraction ratio and particles size of reinforced material is other important factors, which affected the quality of drilled surfaces. Therefore, the independently controllable the drilling parameters that are having large influences on the surface roughness and the delamination in the drilled hole of AL/SiCp (MMCs) specimen has been identified. These parameters are; i) the cutting speed, ii) the feed rate, iii) the tool geometry and the volume fraction ratio is used in this research.

\section{Experimental work}

\subsection{Materials, Tools and Used parameters}

Aluminum 1050 is the base matrix material reinforced with $(15,25$ and $35 \%)$ of Silicon carbide particles of mean diameter $88 \mu \mathrm{m}$ is used. The composite produced by stir casting technique. The experiment carried out on the plate $(200 \times 40 \times 20 \mathrm{~mm})$. Five tools of different point angles twist drills made of highspeed steel (HSS), $\phi 12 \mathrm{~mm}$ is used for the drilling 
operations. The tips of the drills are ground to have drill point angles of $\left(60,70,80,90\right.$ and $\left.100^{\circ}\right)$. To prevent the effect of twist drill wear on the results of the experiments; each of them is used for making five holes only. The cutting parameters are listed in Table (1). The specifications of the used drilling machine are listed in Table (2).

Table (1): The levels used of identified factors.

\begin{tabular}{|l|l|l|l|l|l|}
\hline Parameters & The used levels \\
\hline Feed rate, $\mathrm{mm} / \mathrm{min}$ & 15 & 30 & 45 & 60 & 75 \\
\hline $\begin{array}{l}\text { Tool point angle of } \\
\text { the Tools }\end{array}$ & $60^{\circ}$ & $70^{\circ}$ & $80^{\circ}$ & $90^{\circ}$ & $100^{\circ}$ \\
\hline Cutting speed, rpm & \multicolumn{5}{|c|}{$500,1500,2500$} \\
\hline Volume fraction \% & \multicolumn{5}{|c|}{88,35} \\
\hline Particle size $\mu \mathrm{m}$ & \multicolumn{5}{|c|}{88} \\
\hline
\end{tabular}

Table (2).Specifications of the drilling machine.

\begin{tabular}{|l|c|c|c|c|}
\hline Model & $\begin{array}{c}\text { Drilling } \\
\text { Capacity }\end{array}$ & $\begin{array}{c}\text { Face } \\
\text { Milling } \\
\text { Capacity }\end{array}$ & $\begin{array}{c}\text { End } \\
\text { Milling } \\
\text { Capacity }\end{array}$ & Voltages \\
\hline ZX7032 & $31.5 \mathrm{~mm}$ & $80 \mathrm{~mm}$ & $22 \mathrm{~mm}$ & $\begin{array}{c}380 / 50 \mathrm{HZ} / 150 \\
0 \mathrm{~W}\end{array}$ \\
\hline Speeds & \multicolumn{3}{|l|}{$300, \ldots, \ldots, 700, \ldots, 1000, \ldots, 1200, \ldots, 1500, \ldots, 1700$ and.... } \\
& $2500, \ldots . .$. etc. RPM \\
\hline
\end{tabular}

2.2. Measurement of the surface roughness of the machined holes

The machined holes are prepared for measurements and the measurements of surface roughness performed using SJ- 201P surface test. The measurements are made after the calibration of the instrument and with the cut-off length of $(0.8 \mathrm{~mm})$ according to (ISO 4287-1997). The surface roughness of the hole is measured at entry, middle and exit of the drilled hole and the average value of surface roughness is considered for the investigation.

\section{Results and Discussion}

The analysis of the experimental results has been carried out to study the influence of the following input process parameters; three of cutting speeds (500, 1500 and $2500 \mathrm{rpm}$ ), five of feed rates $(15,30,45,60$ and $75 \mathrm{~mm} / \mathrm{min})$ and five of the drill tools (HSS - different point angles 60, 70, 80, 90 and $100^{\circ}-\varphi$ $12 \mathrm{~mm}$ ) on the process responses, i.e. the delamination (df) and surface roughness ( $\mathrm{Ra}$ ) of the drilled hole (when using three of volume fraction ratios 15, 25 and
$35 \%)$. From the accurate study of the previous works, it is recommended that the proposed methodology of experiments is suitable for analysis the delamination and surface roughness at the drilling of MMC. In the assessment of the delamination (df) and the surface roughness $(\mathrm{Ra})$ all the estimated ratios with respect to the results when used feed rate $15 \mathrm{~mm} / \mathrm{min}$ and tool of point angle $\left(60^{\circ}\right)$.

3.1. Assessment of the delamination (df) and the surface roughness $(\mathrm{Ra})$

\subsubsection{RPM 500 and Vf $15 \%$}

In Figure (1), the relation between the feed rate (f) and the delamination factor (df) with the three drilling parameters is plotted. These parameters are; the cutting speed (500 rpm), five of feed rates [15, 30, 45,60 and $75 \mathrm{~mm} / \mathrm{min}$-(f)], five tools of different point angles $\left(60,70,80,90\right.$ and $\left.100^{\circ}\right)$ and with volume fraction ratio $15 \%$. From this figure, the delamination factor (df) is increased with the increase of the feed rate and increases with the increase of the tool point angle. The increase ratios in (df) when used the tool of point angle $\left(60^{\circ}\right)$ are $0.32,0.43,0.54$ and $0.65 \%$ with the four feed rates $(30,45,60$ and $75 \mathrm{~mm} / \mathrm{min})$. In addition, with feed rate $15 \mathrm{~mm} / \mathrm{min}$, it is increased from; $0.34 \%$ with the tool of point angle $\left(70^{\circ}\right)$ to; 0.45 , 0.57 and to $0.67 \%$ for the other tools $\left(80,90\right.$ and $\left.100^{\circ}\right)$ respectively. When used feed rate $30 \mathrm{~mm} / \mathrm{min}$, the (df) is increased from; $0.32 \%$ with the tool point angle $\left(60^{\circ}\right)$ to; $0.46,0.58$ and 0.65 and to $0.70 \%$ for the other four used tools. In addition, for the other used feed rates 45,60 and $75 \mathrm{~mm} / \mathrm{min}$, the ratios of increase is between; 0.38 and $0.54 \%$ with the tool of point angle $\left(70^{\circ}\right)$. But for the tool of bigger point angle $\left(100^{\circ}\right)$, the values of $(\mathrm{df})$ are; $0.55,0.69$ and $0.71 \%$ for the three feed rates. The low values of (df) are shown with the low feed rate values. The increase of the point angle of the used tool is led also to an obvious increase in the delamination factor (df). From the same results in figure (1), the feed rate is the main parameter, which effects on the delamination factor during drilling. In addition, these results asserted that the tool point angles had large effects on the delamination factor during drilling $\mathrm{MMC}$ when using the mentioned parameters.

In Figure (2), the relation between the feed rate (f) and the surface roughness $(\mathrm{Ra})$ with the same drilling parameters that are used in the previous figure. From 
the results shown in this figure, the surface roughness (Ra) is increased with the increase of the feed rate and increases with the increase of the tool point angle. The surface roughness ( $\mathrm{Ra})$ increased between, 4.0 and $13 \mu \mathrm{m}$ for the used feed rates and with the tool of point angle $\left(60^{\circ}\right)$. With feed rate $15 \mathrm{~mm} / \mathrm{min}$, (Ra) increased from; $4.0 \mu \mathrm{m}$ with the tool of point angle $\left(60^{\circ}\right)$ to; 6.0, 9.0, 11 and $13 \mu \mathrm{m}$ for the others used tools $\left(70,80,90\right.$ and $\left.100^{\circ}\right)$. For the other used feed rates, 30, 45, 60 and $75 \mathrm{~mm} / \mathrm{min}$, the ratios of increase in (Ra) are; 2.0, 2.2, 2.4 and $2.8 \%$ with tool of $\left(70^{\circ}\right)$ and with tool of $\left(80^{\circ}\right)$ point angle, the values of $(\mathrm{Ra})$ are changed to; $2.2,2.4,2.8$ and $2.9 \%$. When used the tool of point angle $\left(90^{\circ}\right)$, the ratios of increase in ( $\left.\mathrm{Ra}\right)$ are; $2.8,3.3,3.9$ and $4.3 \%$ and with the tool of point angle $\left(100^{\circ}\right)$, the ratios of increase are; 3.3, 3.8, 4.1 and $4.5 \%$ for feed rates $30,45,60$ and $75 \mathrm{~mm} / \mathrm{min}$. It is obvious that, the feed rate and the tool point angle are the dominant factors that influence in (Ra) during drilling of MMC at the used parameters.

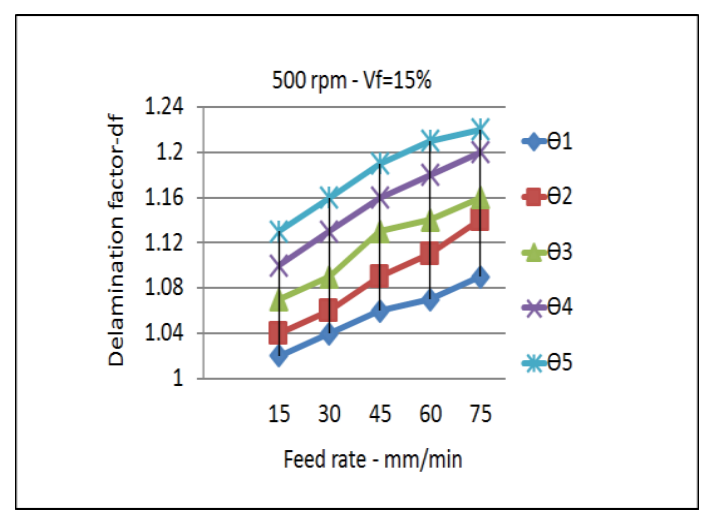

Figure 1: (df - f) Relation at; Vf $=15 \%$, RPM 500 and five tools of different point angles.

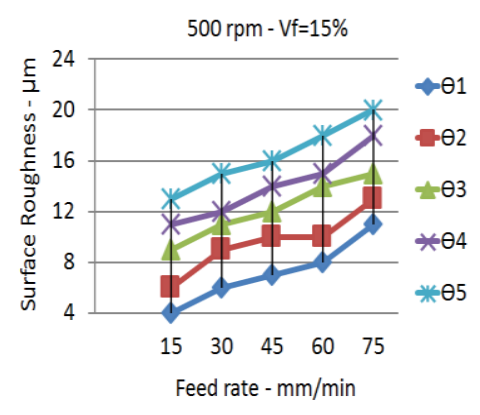

Engineering Research Journal, Menoufiya University, Vol. 42, No. 3, July 2019 
increases with the increase of the tool point angle. The average increase in the values of surface roughness ( $\mathrm{Ra})$ is between, 11 and $18 \mu \mathrm{m}$ for the feed rates $(30,45,60$ and $75 \mathrm{~mm} / \mathrm{min})$ and with the tool of point angle $\left(60^{\circ}\right)$. With feed rate $15 \mathrm{~mm} / \mathrm{min}$, the ratios of increase in the surface roughness $(\mathrm{Ra})$ are from; $2.2 \%$ with the tool of point angle $\left(70^{\circ}\right)$ to 2.7 , 3.2 , and $3.7 \%$ for the others used tools. When used feed rate $30 \mathrm{~mm} / \mathrm{min}$, the surface roughness ( $\mathrm{Ra}$ ) is increased from; $2.6 \%$ with the tool point angle $\left(70^{\circ}\right)$ to $3.1,3.6$ and $4.1 \%$ for the other three used tools. The increase ratios in ( $\mathrm{Ra}$ ) for the other feed rates 45,60 and $75 \mathrm{~mm} / \mathrm{min}$ are; 3.4, 3.9 and $4.4 \%$ with tool of $\left(70^{\circ}\right)$ and with tool of $\left(80^{\circ}\right)$ point angle the values are changed to; $3.6,4.1$ and $4.6 \%$. For the tool of point angle $\left(90^{\circ}\right)$, the values are; 3.8, 4.3 and $4.8 \%$ and when used the tool of point angle $\left(100^{\circ}\right)$, the increase ratios of $(\mathrm{Ra})$ are; 4.1, 4.6 and $5.1 \%$ for the same feed rates. The increase of volume fraction ratio to $25 \%$ with the same used parameters is led to an increase in the values of surface roughness ( $\mathrm{Ra}$ ). In addition, the feed rate and the tool point angle are had a large effect on the resultant values of the surface roughness (Ra) at the used parameters. From the comparison between the results when using; the five used tools, (Vf-15\%) and the cutting speed $500 \mathrm{rpm}$, with the results in Fig. (4) When used the same parameters but the volume fraction (Vf) is changed to $25 \%$, the analysis of these results indicated that; the change of (Vf) from 15 to $25 \%$ leads to an increase in all values of the surface roughness ( $\mathrm{Ra})$. The ratios of increase in (Ra) when used feed rate $15 \mathrm{~mm} / \mathrm{min}$ and with the five used tools are; 1.04, 1.05, 1.06 and 1.07 and to 1.08 $\%$. When used feed rate $75 \mathrm{~mm} / \mathrm{min}$ and the five used tools, the ratios of increase in the surface roughness (Ra) are; $1.71,2.18,2.34$ and 2.39 and to $2.6 \%$ respectively. It is obvious that, from this comparison, the values of increase in ( $\mathrm{Ra}$ ) increased with the increase of feed rate and with the increase of the point angle of the used tools between (VF, 15 and $25 \%$ ) with the same cutting speed $500 \mathrm{rpm}$.

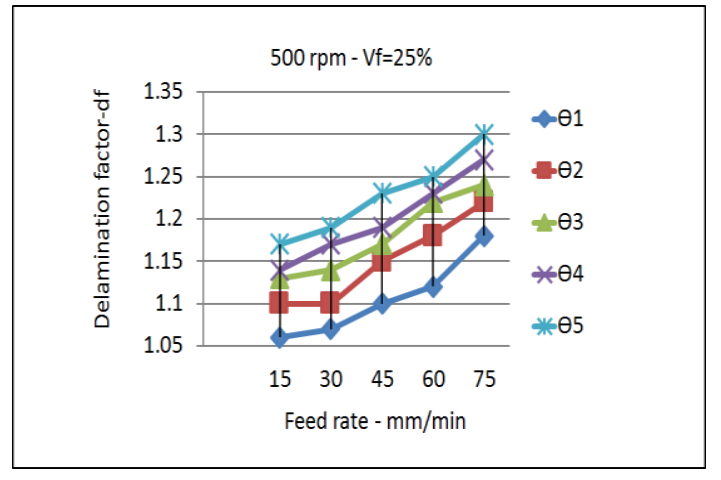

Figure 3: (df - f) Relation at; Vf $=25 \%, R P M 500$ and five tools of different point angles.

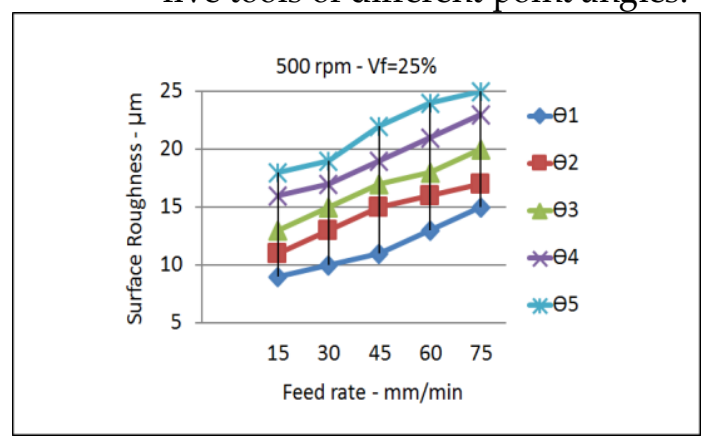

Figure 4: (Ra - f) Relation at; Vf $=25 \%$, RPM 500 and five tools of different point angles.

\section{1.3.RPM 500 and Vf $35 \%$}

In Figure (5), the volume fraction ratio is changed from, 25 to $35 \%$. The delamination factor (df) are increased with the increase of feed rate and increases with the increase of tool point angle. The increase ratios in (df) are between; 0.39 and $0.72 \%$ when used tool of point angle $\left(70^{\circ}\right)$ and with the four feed rates (30, 45, 60 and75 $\mathrm{mm} / \mathrm{min})$. The increase ratios with the used feed rates is between; 0.49 and $0.74 \%$ when used the tool of point angle $\left(80^{\circ}\right)$. With the tool of point angle $\left(90^{\circ}\right)$, it is increased between; 0.55 and $0.78 \%$. But for the tool of point angle $\left(100^{\circ}\right)$, the ratios are changed to; 0.68 to $0.69,0.72,0.76$ and $0.79 \%$. The volume fraction ratio, feed rate and tool point angle are the dominant factors that influence in the resultant values of the delamination factor (df) at the used parameters. From the previous results, it has been observed that, the low feed rate $(15 \mathrm{~mm} / \mathrm{min})$ and the tool of small point angle $\left(60^{\circ}\right)$ are given a less values of (df) during drilling when using volume fraction of $35 \%$ with cutting speed $500 \mathrm{rpm}$. The change of (Vf) from 15 to 35\%, when used the same parameters with cutting speed $500 \mathrm{rpm}$, leads to an 
increase in all values of (df). The increase ratios in (df) when used feed rate $15 \mathrm{~mm} / \mathrm{min}$ and with the five used tools are; 1.02, 1.05, 1.13 and 1.14 and to 1.15 $\%$. In addition, with the feed rate of $75 \mathrm{~mm} / \mathrm{min}$ and the same used tools, the ratios of increase in (df) are; $1.11,1.30,1.33$ and 1.34 and to $1.48 \%$ respectively. It is obvious that, from this comparison, the ratios of increase are more with the increase of the feed rate and with the increase of the point angle of the used tools between (VF, 15 and 35\%) with the same cutting speed $500 \mathrm{rpm}$.

From Figure (6), the surface roughness (Ra) increased with the increase of feed rate and increases with the increase of tool point angle. With feed rates $(30,45,60$ and75 $\mathrm{mm} / \mathrm{min}$ ) and tool of point angle $\left(60^{\circ}\right)$, the average increase in ( $\mathrm{Ra})$ is between; 10 and $15 \mu \mathrm{m}$. When used feed rate $15 \mathrm{~mm} / \mathrm{min}$, the average increase in ( $\mathrm{Ra}$ ) with the increase of tool point angle is between; 9.0 to $19 \mu \mathrm{m}$. The average increase in (Ra) with the increase of tool of point angle are from; 13 to 16 and 17 and to $20 \mu \mathrm{m}$ for the used tools and with feed rate $30 \mathrm{~mm} / \mathrm{min}$. When used the other feed rates (45, 60 and $75 \mathrm{~mm} / \mathrm{min}$ ), the average increase in (Ra) is between; 12 to $15 \mu \mathrm{m}$ with the tool of $\left(60^{\circ}\right)$ and 15 to17 $\mu \mathrm{m}$ with the tool of $\left(70^{\circ}\right)$ point angle. The ratios of increase in $(\mathrm{Ra})$ when used the tool of point angle $\left(80^{\circ}\right)$ are; 3.8, 4.3 and $4.8 \%$ and for the tool of point angle $\left(90^{\circ}\right)$, the values are changed to; $4.1,4.5$ and $5.1 \%$ for the same feed rates 45,60 and $75 \mathrm{~mm} / \mathrm{min}$. When the tool of point angle $\left(100^{\circ}\right)$, the ratios of increase in (Ra) are; 4.4, 4.9 and $5.4 \%$ for the same three feed rates. The feed rate and tool point angle are had the most dominant influence in the resultant values of surface roughness ( $\mathrm{Ra})$ at the used parameters. The change of (Vf) ratio from 25 to $35 \%$ with the same used parameters is led to an increase in the values of surface roughness $(\mathrm{Ra})$.

The change of (Vf) from 15 to $35 \%$, when used the same parameters with cutting speed $500 \mathrm{rpm}$, leads to an increase in all values of the surface roughness (Ra). The percentages of increase in ( $\mathrm{Ra}$ ) when used feed rate $15 \mathrm{~mm} / \mathrm{min}$ and with the five used tools are; 1.17, $1.18,1.27$ and 1.29 and to $1.45 \%$. When used feed rate $75 \mathrm{~mm} / \mathrm{min}$ and the five used tools, the ratios of increase in the surface roughness (Ra) are; 1.19, 1.2, 1.61 and 1.66 and to $1.68 \%$ respectively. From this comparison, the ratios of increase in ( $\mathrm{Ra}$ ) increased with the increase of the feed rate and with the increase of the point angle of the used tools and between (VF, 15 and 35\%) with the same cutting speed $500 \mathrm{rpm}$.

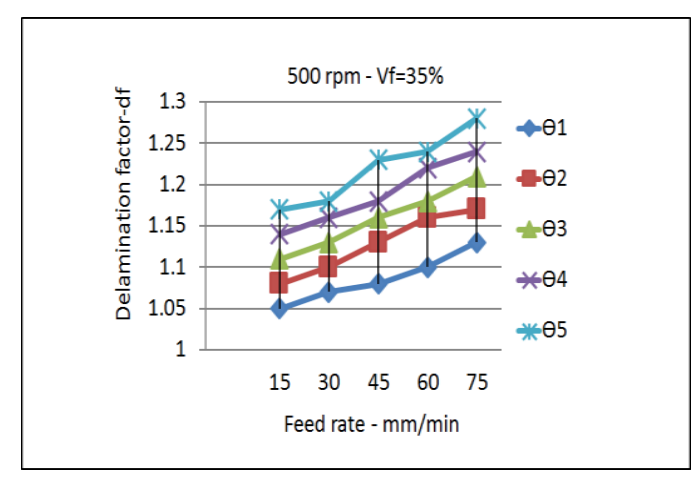

Figure 5: (df - f) Relation at; Vf =35\%, RPM 500 and five tools of different point angles.

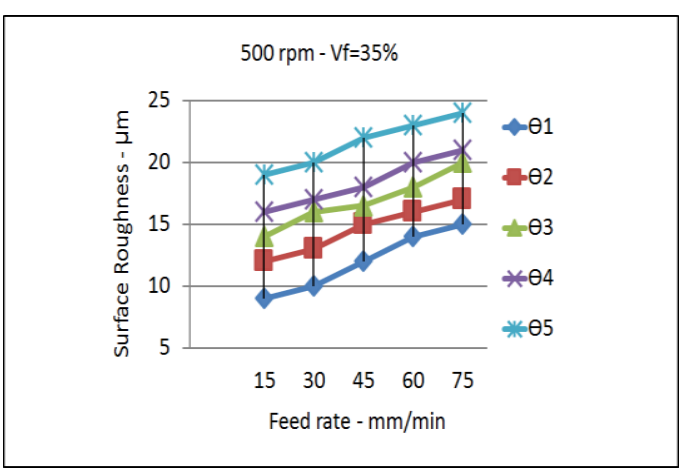

Figure 6: (Ra - f) Relation at; Vf =35\%, RPM 500 and five tools of different point angles.

From Figure (7), the delamination factor (df) is increased with the increase of feed rate and increases with the increase of tool point angle. The increase ratios of (df) when used to feed rate $15 \mathrm{~mm} / \mathrm{min}$ is between; $0.49 \%$ with the tool of point angle $\left(70^{\circ}\right)$ to $0.52,0.64$, and to $0.72 \%$ for the other tools $(80,90$ and $\left.100^{\circ}\right)$. When used feed rate $30 \mathrm{~mm} / \mathrm{min}$, the ( $\left.\mathrm{df}\right)$ is increased from; $0.38 \%$ with tool point angle $\left(60^{\circ}\right)$ to 0.52 and $0.64,0.74$ and to $0.76 \%$ for the other used tools. When used feed rates $(45,60$ and $75 \mathrm{~mm} / \mathrm{min})$, the ratios of increase in (df) are; 0.44 and 0.52 and $0.67 \%$ with tool of $\left(70^{\circ}\right)$ and with tool of $\left(80^{\circ}\right)$ point angle these ratios are changed to; $0.59,0.64$ and $0.68 \%$. For the tool of point angle $\left(100^{\circ}\right)$, the ratios of increase in (df) are; $0.65,0.74$ and $0.78 \%$ for the same feed rates. The comparison between the results when used cutting speed $500 \mathrm{rpm}$, the five used tools, feed rate $15 \mathrm{~mm} / \mathrm{min}$ and $(\mathrm{Vf}=15 \%)$ with the same 
parameters but the cutting speed is changed to 1500 $\mathrm{rpm}$, the analysis indicated that, the increase in cutting speed leads to an increase in the delamination factors (df) .The ratios of increase are; $1.11 \%$ with the tool of point angle $\left(60^{\circ}\right)$ to $1.15,1.16$ and 1.28 and to $1.34 \%$ for the other four tools $\left(70,80,90\right.$ and $100^{\circ}$ ) with feed rate $75 \mathrm{~mm} / \mathrm{min}$ and the same used parameters, the ratios of increase in (df) are; 1.13, $1.19,1.24$ and 1.33 and to $1.38 \%$ for the used tools. It is apparent that, the feed rate and the point angle of the tool play an important role in the resultant values of delamination factor ( $\mathrm{df}$ ) at the used parameters. The increase of cutting speed from 500 to $1500 \mathrm{rpm}$ with the same volume fraction ratio $15 \%$ is led to an obvious increase in the values of delamination factor (df).

From the results shown in Figure (8), the ratios of increase in ( $\mathrm{Ra})$ with the increase of the tool point angle are from; $2.0 \%$ with tool of point angle $\left(70^{\circ}\right)$ to; 2.2, 2.6 and $3.0 \%$ for the other tools and with feed rate $15 \mathrm{~mm} / \mathrm{min}$. When used feed rate $30 \mathrm{~mm} / \mathrm{min}$, (Ra) increased also from; $2.3 \%$ with tool point angle $\left(70^{\circ}\right)$ to $2.5,2.7$ and $3.2 \%$ for the other three used tools. For the other used feed rates 45,60 and 75 $\mathrm{mm} / \mathrm{min}$, the ratios of increase in ( $\mathrm{Ra}$ ) are changed to; 2.3, 2.4 and $2.7 \%$ with the tool of $\left(70^{\circ}\right)$ and $2.4,2,7$ and $2,8 \%$ with the tool of $\left(80^{\circ}\right)$ point angle respectively. When used the same feed rates and with the tool of point angle $\left(90^{\circ}\right)$, the ratios of increase in ( $\mathrm{Ra}$ ) are; 3.6, 3.9 and $4.2 \%$ and changed to; $3.9,4.2$ and $4.3 \%$ when used tool of point angle $\left(100^{\circ}\right)$. The comparison between the results when used ( $\mathrm{Vf}=15 \%)$ and the cutting speed is changed from 500 to $1500 \mathrm{rpm}$ with the same parameters, the analysis indicated that, the increase in the cutting speed leads to a decrease in (Ra). In addition, the ratios of decrease in ( $\mathrm{Ra})$ are; $0.71 \%$ with tool of point angle $\left(60^{\circ}\right)$ to $0.82,0.83$, 0.88 and $0.97 \%$ for the other used tools. Moreover, with feed rate $75 \mathrm{~mm} / \mathrm{min}$ and the same parameters, the ratios of decrease in (Ra) are; 0.94, 0.95, 0.96 and 0.97 and to $0.99 \%$ for all used tools. It is evident that the cutting speed has more influence in the resultant values of surface roughness ( $\mathrm{Ra}$ ) at all used parameters. Furthermore, the results in the previous figure demonstrated a very strong association between the resultant surface roughness (Ra) with, feed rate and the tool point angle when change cutting speed from 500 to $1500 \mathrm{rpm}$.

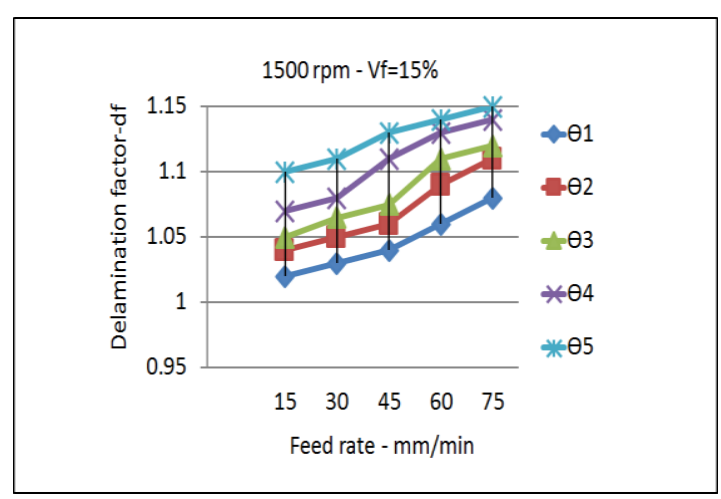

Figure 7: (df - f) Relation at; Vf =15\%, RPM 1500 and five tools of different point angles.

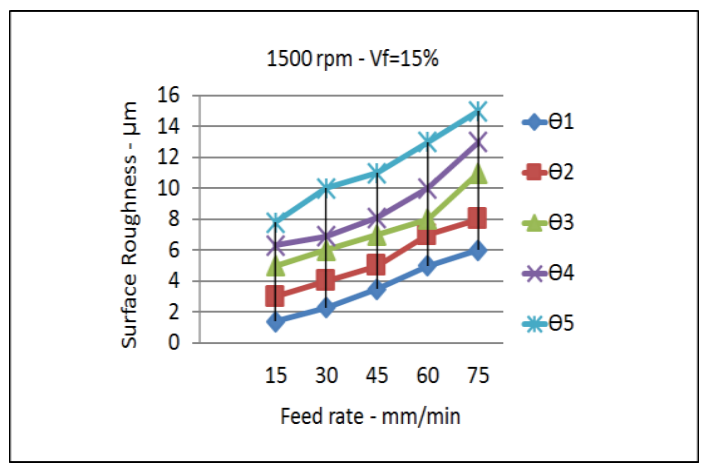

Figure 8: (Ra- f) Relation at; Vf $=15 \%, \mathrm{RPM} 1500$ and five tools of different point angles.

\section{2.1. RPM 1500 and Vf $\mathbf{2 5 \%}$}

In Figure (9), the volume fraction ratio (Vf) is changed from, 15 to $25 \%$ with feed rate $30 \mathrm{~mm} / \mathrm{min}$ and the ratios of increase in (df) are from; 0.54 with the tool of point angle $\left(70^{\circ}\right)$ to $0.55,0.64$ and $0.72 \%$ for the other used tools. When used the other feed rates 45,60 and $75 \mathrm{~mm} / \mathrm{min}$, the ratios of increase are between; 0.56 and $0.69 \%$ with the tool of $\left(70^{\circ}\right)$ and 0.61 and $0.73 \%$ with tool of point angle $\left(80^{\circ}\right)$. For the same feed rates, the ratios of increase when used tool of point angle $\left(100^{\circ}\right)$ are; $0.67,0.76$ and $0.81 \%$. The increase of (Vf) from 15 to $25 \%$, when used the same parameters with cutting speed $1500 \mathrm{rpm}$, leads to an increase in all values of (df). The ratios of increase in (df) when used feed rate $15 \mathrm{~mm} / \mathrm{min}$ and with the used tools are; 1.01, 1.02, 1.03 and 1.04 and to $1.06 \%$. In addition, with the feed rate of $75 \mathrm{~mm} / \mathrm{min}$ and the five used tools, the ratios of increase in the delamination factor (df) are1.03, 1.04, 1.05 and 1.07 and to $1.12 \%$ respectively. 
The comparison between the results when used cutting speed $500 \mathrm{rpm}$, the five used tools, feed rate $15 \mathrm{~mm} / \mathrm{min}$ and (Vf) $25 \%$ with the same parameters when used cutting speed $1500 \mathrm{rpm}$, the analysis indicated that, the increase in cutting speed leads to an increase in (df). The ratios of increase in (df) are, $1.04 \%$ with tool of point angle $\left(60^{\circ}\right)$ to $1.06,1.06$ and 1.12 and to $1.28 \%$ for the other four tools $(70,80,90$ and $\left.100^{\circ}\right)$. Furthermore, with feed rate $75 \mathrm{~mm} / \mathrm{min}$ and the same parameters, the ratios of increase in (df) are; $1.07,1.08,1.10,1.22$ and $1.34 \%$ for the uses tools. From these analyses, the values in the delamination factor (df) are increased with the increase of the feed rate and with the increase of the point angle of the used tools when changed cutting speed from 500 to $1500 \mathrm{rpm}$ with volume fraction ratio ( $\mathrm{VF}=25 \%)$.

In Figure (10), the plotted results indicated that, the increase in the feed rate leads to an increase in the surface roughness of machined hole, and the surface roughness ( $\mathrm{Ra}$ ) also increases with the increase of the tool point angle. With feed rate $15 \mathrm{~mm} / \mathrm{min}$, the ratios of increase in (Ra) are from; $2.1 \%$ with the tool of point angle $\left(70^{\circ}\right)$ to $2.6,3.1$ and $3.6 \%$ for the others used tools. For feed rate $30 \mathrm{~mm} / \mathrm{min}$, the ratios of increase are changed to; 2.2, 2.6 and 3.2 and to $3.7 \%$ for the four used tools. The ratios of increase in (Ra) for the other used feed rates 45,60 and $75 \mathrm{~mm} / \mathrm{min}$ are; 3.1, 3.5 and $4.5 \%$ with tool of $\left(70^{\circ}\right)$ and 3.2, 3.6 and $4.6 \%$ with tool of $\left(80^{\circ}\right)$. For the tools of point angles $\left(90^{\circ}\right.$ and $\left.100^{\circ}\right)$, the increase in surface roughness ( $\mathrm{Ra}$ ) are; 3.4, 3.8 and $4.7 \%$ and 3.6, 3.9and $4.8 \%$ for the three feed rates. The increase of $(\mathrm{Vf})$ from 15 to $25 \%$ when used the same parameters with cutting speed $1500 \mathrm{rpm}$ leads to an increase in all values of the surface roughness (Ra). The ratios of increase in (Ra) when used feed rate $15 \mathrm{~mm} / \mathrm{min}$ and with the used tools are; 1.03, 1.04, 1.05, 1.08 and 1.11 $\%$. With the feed rate of $75 \mathrm{~mm} / \mathrm{min}$ and the five used tools, the ratios of increase in ( $\mathrm{Ra})$ are changed to; $1.04,1.06,1.07,1.09$ and $1.13 \%$ respectively. From the comparison, it is clear that, the ratios of increase in (Ra) are increased with the increase of feed rate and with the increase of point angle of the used tools between (VF, 15 and 25\%) with the same cutting speed $1500 \mathrm{rpm}$.

In the other side, the comparison between the results when used cutting speed $500 \mathrm{rpm}$, the five used tools , feed rate $15 \mathrm{~mm} / \mathrm{min}$ and $(\mathrm{Vf}=25 \%$ ) with the same parameters when used cutting speed $1500 \mathrm{rpm}$, the analysis indicated that, the increase in cutting speed leads to a decrease in the surface roughness (Ra). The ratios of decrease in ( $\mathrm{Ra})$ are; $0.62 \%$ with tool of point angle $\left(60^{\circ}\right)$ to $0.64,0.65,0.67$ and $0.69 \%$ for the other used tools. Moreover, with feed rate $75 \mathrm{~mm} / \mathrm{min}$ and the same parameters, the ratios of decrease in ( $\mathrm{Ra})$ are; $0.70,0.81,0.86,0.87$ and $0.95 \%$ for all used tools.

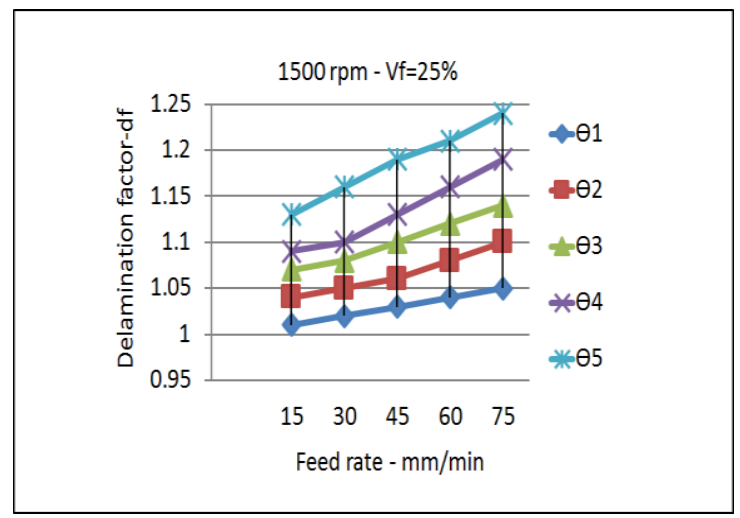

Figure 9: (df - f) Relation at; Vf =25\%, RPM 1500 and five tools of different point angles.

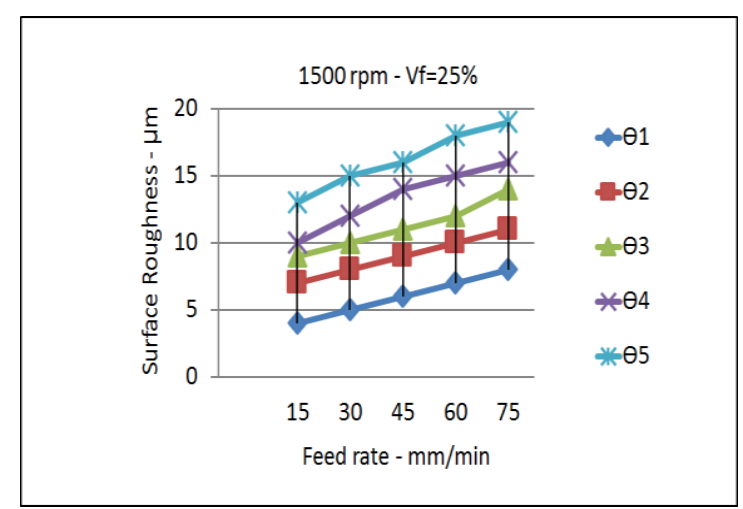

Figure 10: (Ra- f) Relation at; Vf =25\%, RPM 1500 and five tools of different point angles.

\section{2.2. RPM 1500 and $V f 35 \%$}

In Figure (11), the volume fraction ratio is increased to $35 \%$. The delamination factor (df) is increased with the increase of the feed rate and increases with the increase of tool point angle. The average increase in (df) is between; 1.02 and 1.09 for the used feed rates and with the tool of point angle $\left(60^{\circ}\right)$. When feed rate $15 \mathrm{~mm} / \mathrm{min}$, the average increase is between, 1.02 to 1.18 for the used tools $\left(60,70,80,90\right.$ and $\left.100^{\circ}\right)$. When used feed rate $30 \mathrm{~mm} / \mathrm{min}$, the ratios of increase in (df) are from; $0.46 \%$ with tool point angle $\left(70^{\circ}\right)$ to 
0.57 and 0.68 and to $0.78 \%$ for the other used tools. For feed rates 45,60 and $75 \mathrm{~mm} / \mathrm{min}$, the ratios of increase in (df) are; $0.50,0.57$ and $0.73 \%$ with tool of $\left(70^{\circ}\right)$ and with the tool of $\left(80^{\circ}\right)$ point angle, the values are changed to; $0.65,0.70$ and $0.75 \%$ with the same three feed rates, and for the tool of point angle $\left(90^{\circ}\right)$, the values are; $0.69,0.74$ and $0.79 \%$. For the tool of point angle $\left(100^{\circ}\right)$, the values changed to; $0.75,0.80$ and $0.85 \%$ for the three feed rates 45,60 and 75 $\mathrm{mm} / \mathrm{min}$. The increase of volume fraction ratio from 25 to $35 \%$ with the same used parameters is led to an increase in the values of delamination factor (df). In addition, the feed rate and the tool point angle are the most significant factors, which affect in the values of delamination factor ( $\mathrm{df}$ ) at the used parameters. Furthermore, the change of (Vf) from 15 to $35 \%$ when used the same parameters with cutting speed 1500 rpm leads to an increase in all values of (df). The ratios of increase in (df) when used feed rate 15 $\mathrm{mm} / \mathrm{min}$ and with the used tools are; 1.02, 1.04, 1.05, 1.11 and $1.15 \%$. In addition, with the feed rate of $75 \mathrm{~mm} / \mathrm{min}$ and the five used tools, the ratios of increase in (df) are; 1.05, 1.07, 1.09, 1.19 and 1.21\% respectively. From the analysis of the results, the values of increase in (df) are increased with the increase of feed rate and with the increase of the point angle of the used tools between (VF, 15 and $35 \%$ ) with the same cutting speed1500 rpm.

The comparison between the results when used cutting speed $500 \mathrm{rpm}$, the five used tools, feed rate $15 \mathrm{~mm} / \mathrm{min}$ and (Vf )is changed to $35 \%$ with the same parameters when used cutting speed $1500 \mathrm{rpm}$, the analysis indicated that, the increase in cutting speed and (Vf ) are led to an increase in the delamination factors (df). The ratios of increase in (df) are; $1.04 \%$ with tool of point angle $\left(60^{\circ}\right)$ to $1.06,1.09,1.13$ and $1.15 \%$ for the other four tools $\left(70,80,90\right.$ and $\left.100^{\circ}\right)$. In addition, with feed rate $75 \mathrm{~mm} / \mathrm{min}$ and the same parameters, the ratios of increase in (df) are; 1.10, $1.24,1.28,1.30$ and $1.32 \%$ for the uses tools.

From Figure (12), the results indicated that, the surface roughness (Ra) increased with the increase of feed rate and increases with the increase of the tool point angle. With feed rate $15 \mathrm{~mm} / \mathrm{min}$, the ratios of increase in $(\mathrm{Ra})$ are from;
$2.3 \%$ with tool of point angle $\left(70^{\circ}\right)$ to $2.5,2.8$ and 3.2 $\%$ for the others used tools. The ratios of increase in (Ra) for feed rates 30, 45, 60 and $75 \mathrm{~mm} / \mathrm{min}$ and with tool of point angle $\left(60^{\circ}\right)$ are; $2.9, ; 3.4,3.8$ and to $4.3 \%$. For the tools of $\left(70^{\circ}, 80^{\circ}, 90^{\circ}\right.$ and $\left.100^{\circ}\right)$ and feed rate $30 \mathrm{~mm} / \mathrm{min}$, the ratios of increase are; $2.6 \%$ with tool point angle $\left(70^{\circ}\right)$ to $3.0,3.8$ and $4.4 \%$ with the other tools. When used feed rate $45 \mathrm{~mm} / \mathrm{min}$, the values is between; 3.0 and $4.5 \%$ for the four used tools. The ratios of increase in (Ra) for the feed rates 60 and $75 \mathrm{~mm} / \mathrm{min}$ are; 3.3 and $3.6 \%$ with tool of $\left(70^{\circ}\right)$ and with tool of $\left(80^{\circ}\right)$ point angle the values are changed to; 3.6 and $4.0 \%$. For the tools of point angles $\left(90^{\circ}\right.$ and $\left.100^{\circ}\right)$, the values are; 3.9 and $4.7 \%$ and 4.1 and $4.9 \%$ for the two feed rates 60 and 75 $\mathrm{mm} / \mathrm{min}$. The increase of volume fraction from 25 to $35 \%$ with the same used parameters led to an increase in the values of ( $\mathrm{Ra}$ ). In addition, the feed rate and tool point angle are had dominant influence in the resultant values of $(\mathrm{Ra})$ at the used parameters. The increase of $(\mathrm{Vf})$ from 15 to $35 \%$ when used the same parameters with cutting speed $1500 \mathrm{rpm}$ leads to an increase in all values of the surface roughness (Ra). The ratios of increase in ( $\mathrm{Ra}$ ) when use feed rate $15 \mathrm{~mm} / \mathrm{min}$ and with the used tools are; 1.02, 1.03, $1.05,1.07$ and $1.09 \%$. In addition, with feed rate $75 \mathrm{~mm} / \mathrm{min}$ and the five used tools, the ratios of increase in (Ra) are changed to; 1.03, 1.07, 1.12, 1.17 and $1.25 \%$ respectively. From this comparison, the ratios of increase in (Ra) increased with the increase of the feed rate and with the increase of the point angle of the used tools between (VF, 15 and 35\%) with the same cutting speed $1500 \mathrm{rpm}$. From the comparison between the results when used cutting speed $500 \mathrm{rpm}$, the five used tools, feed rate 15 $\mathrm{mm} / \mathrm{min}$ and $(\mathrm{Vf}=25 \%)$ with the same parameters when used cutting speed $1500 \mathrm{rpm}$, the analysis indicated that, the increase in cutting speed leads to a decrease in the surface roughness (Ra). The ratios of decrease in (Ra) are; $0.62 \%$ with tool of point angle $\left(60^{\circ}\right)$ to $0.67,0.68,0.72$ and $0.74 \%$ for the other used tools. With feed rate $75 \mathrm{~mm} / \mathrm{min}$ and the same parameters, the ratios of increase in ( $\mathrm{Ra}$ ) are; 0.70, $0.81,0.86,0.89$ and $0.95 \%$ for all used tools. 


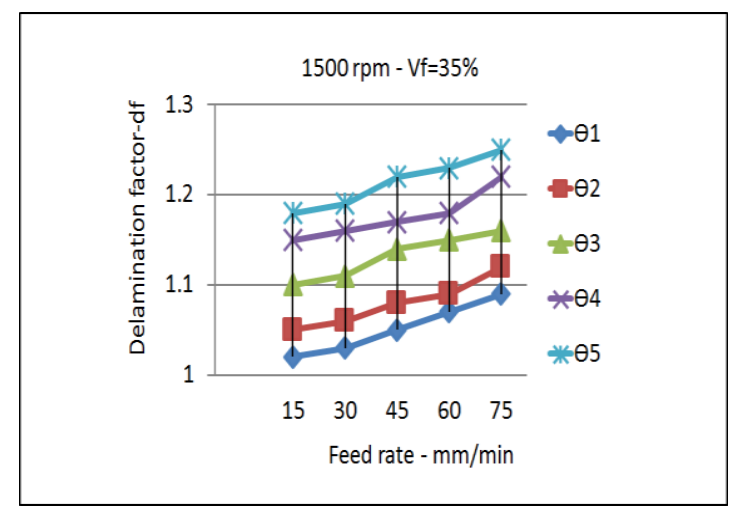

Figure 11: (df - f) Relation at; Vf =35\%, RPM 1500 and five tools of different point angles.

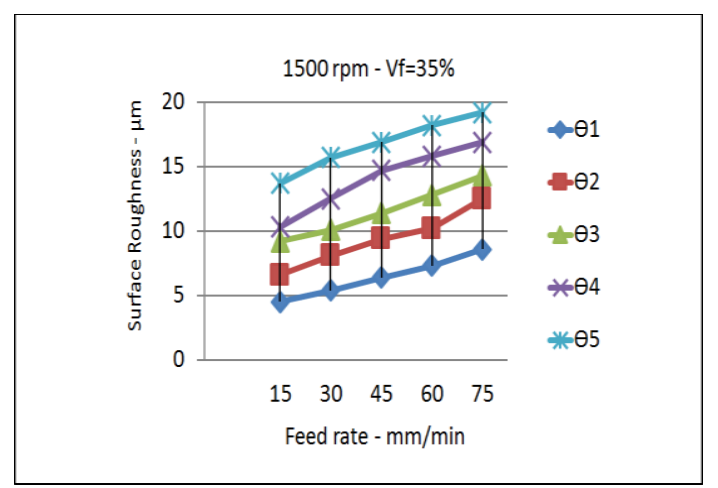

Figure 12: (Ra- f) Relation at; Vf $=35 \%$, RPM 1500 and five tools of different point angles.

\subsection{RPM 2500 and Vf $15 \%$}

The relation between feed rate (f) and delamination factor (df) with three parameters is plotted in Figure (13). These parameters used in the previous experiment, but the cutting speed is increased to 2500 rpm and volume fraction ratio is changed also to $15 \%$. In these results, the delamination factor ( $\mathrm{df}$ ) is increased with the increase of feed rate and increases with the increase of the tool point angle. The average increase in (df) is between; 1.01 to 1.11 with the used tools and at feed rate $15 \mathrm{~mm} / \mathrm{min}$. For the used feed rates $30,45,60$ and $75 \mathrm{~mm} / \mathrm{min}$, the ratios of increase in (df) are; $0.53,0.65,0.75$ and $0.81 \%$ with the tool of $\left(60^{\circ}\right)$ and with the tool of $\left(70^{\circ}\right)$ point angle, the ratios of increase are changed to; $0.55,0.66,0.78$ and $0.85 \%$ and for the tool of point angle $\left(80^{\circ}\right)$, the values are; $0.60,0.68,0.77$ and $0.87 \%$. With the tools of point angles $\left(90\right.$ and $\left.100^{\circ}\right)$, the ratios of increase are; 0.69 , $0.78,0.86$ and $0.89 \%$ and $0.70,0.74,0.84$ and $0.92 \%$ with the same feed rates. The feed rate and the point angle of the tool play a strong role in the resultant values of delamination factor ( $\mathrm{df}$ ) at the used parameters. In addition, the change of cutting speed to $2500 \mathrm{rpm}$ with the same used parameters is led to an increase in the values of delamination factor (df). The increase of the cutting speed from 1500 to 2500 rpm when used the same parameters with feed rate $15 \mathrm{~mm} / \mathrm{min}$ and $(\mathrm{VF}=15 \%)$ leads to an increase in all values of (df). The ratios of increase in (df) are; 1.02 $\%$ with tool of point angle $\left(60^{\circ}\right)$ to; $1.03,1.05,1.07$ and $1.09 \%$ for the other four tools $\left(70,80,90\right.$ and $\left.100^{\circ}\right)$. With feed rate $75 \mathrm{~mm} / \mathrm{min}$ and the same parameters, the ratios of increase in (df) are; 1.13, 1.15, 1.21, 1.22 and 1.31 for the used tools.

The relation between feed rate (f) and surface roughness $(\mathrm{Ra})$ with three drilling parameters; the cutting speed (2500rpm), the used feed rates, the used tools and with volume fraction ratio, $15 \%$ plotted in Figure (14). The ratios of increase in ( $\mathrm{Ra}$ ) for feed rates $30,45,60$ and $75 \mathrm{~mm} / \mathrm{min}$ and with tool of point angle $\left(60^{\circ}\right)$ are; $2,2,2.4,2.6$ and to $2.9 \%$. When used feed rate $15 \mathrm{~mm} / \mathrm{min}$, the ratios of increase in (Ra) are; $2.3 \%$ with tool of point angle $\left(70^{\circ}\right)$ to $2.5,2.7$ and 3.0 $\%$ for the others tools $\left(80,90\right.$ and $100^{\circ}$ ) respectively. For the tools of $\left(70,80,90\right.$ and $\left.100^{\circ}\right)$ point angles and feed rate $30 \mathrm{~mm} / \mathrm{min}$, the ratios of increase are; $2.4 \%$ with the tool of point angle $\left(70^{\circ}\right)$ and changed to 2.8 , 3.4 and $4.5 \%$ with the other used tools. With feed rate $45 \mathrm{~mm} / \mathrm{min}$, and with the four used tools, the ratios are changed to; 3.2, 3.6, 4.4 and $4.6 \%$. The ratios of increase in (Ra) for the other used feed rates 60 and 75 $\mathrm{mm} / \mathrm{min}$ are; 3.4 and $3.7 \%$ with tool of $\left(70^{\circ}\right)$ and with tool of $\left(80^{\circ}\right)$ point angle the values are changed to; 3.9 and $4.2 \%$. With the tools of point angles (90 and $\left.100^{\circ}\right)$, the percentages of increase are; 4.3 , and $4.4 \%$ and 4,5 and $4.7 \%$ for the same feed rates. It is noticeable that, the cutting speed plays important role in the resultant values of the surface roughness (Ra), also, the feed rate and point angle of the tool are had a large effect in the resultant values of $(\mathrm{Ra})$ at the used parameters.

The increase of the cutting speed from 1500 to 2500 rpm when used the same parameters with feed rate $15 \mathrm{~mm} / \mathrm{min}$ and $(\mathrm{VF}=15 \%)$ leads to a decrease in all values of the surface roughness $(\mathrm{Ra})$. The ratios of decrease in (Ra) are; $0.55 \%$ with tool of point angle $\left(60^{\circ}\right)$ to; $0.68,0.78,0.84,0.92 \%$ for the other used tools. With feed rate $75 \mathrm{~mm} / \mathrm{min}$ and the same 
parameters, the ratios of decrease in (Ra) are; 0.90, $0.91,0.93,0.95$ and $0.98 \%$ for all used tools.

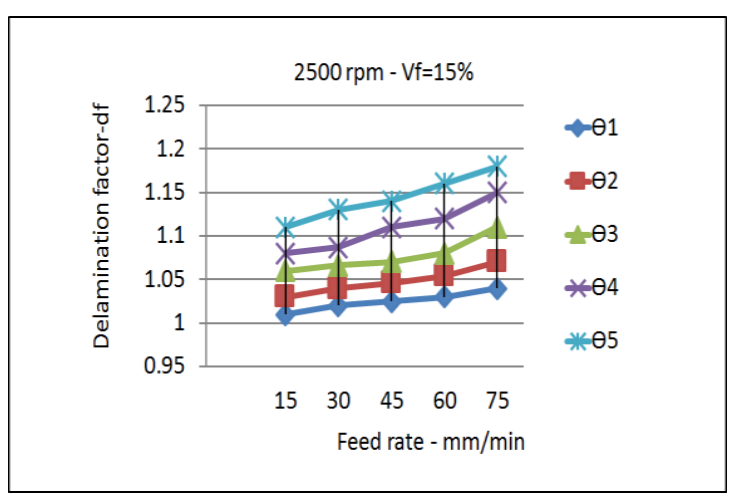

Figure 13: (df - f) Relation at; $\mathrm{Vf}=15 \%, \mathrm{RPM} 2500$ and five tools of different point angles.

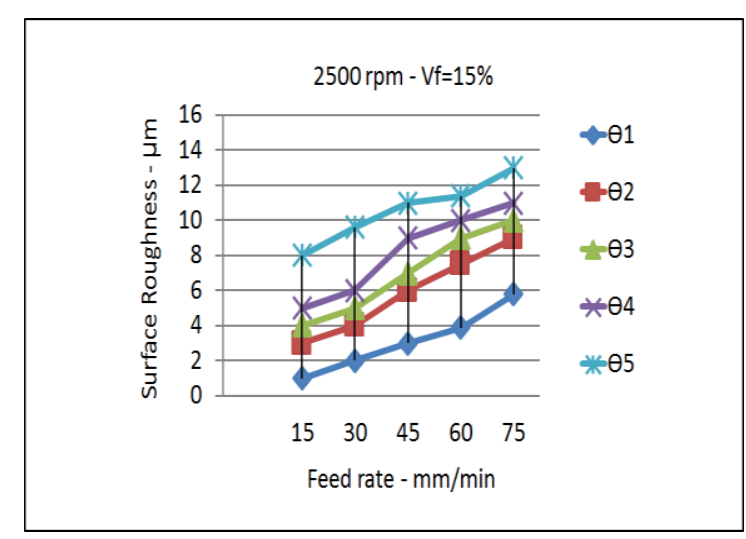

Figure 14: (Ra- f) Relation at; Vf $=15 \%$, RPM 2500 and five tools of different point angles.

\subsubsection{RPM 2500 and Vf $25 \%$}

In Fig. (15), the same parameters used in the previous figure, but the volume fraction is changed from 15 to $25 \%$. The average increase in ( $\mathrm{df}$ ) is between; 1.021 to 1.071 for the used feed rates and the used tools. With feed rates; 30, 45, 60 and $75 \mathrm{~mm} / \mathrm{min}$, the ratios of increase in (df) are; $0.54,0.66,0.76$ and $0.82 \%$ with tool of $\left(60^{\circ}\right)$ and the ratios of increase are changed to; $0.57,0.68,0.79$ and $0.86 \%$ with the tool of $\left(70^{\circ}\right)$ point angle. For the tools of point angles $\left(90\right.$ and $\left.100^{\circ}\right)$, the ratios of increase are changed to; $0.72,0.82,0.89$ and $0.92 \%$ and $0.76,0.80,0.86$ and $0.94 \%$ with the same feed rates. From the results, the volume fraction, feed rate and the tool point angle are play a vital role in the resultant values of delamination factor (df) at the used parameters. The increase of (Vf) from 15 to $25 \%$ when used the same parameters with cutting speed
$2500 \mathrm{rpm}$ leads to an increase in all values of (df). The ratios of increase in (df) with feed rate $15 \mathrm{~mm} / \mathrm{min}$ and the five used tools are; 1.12, 1.13, 1.18, 1.22 and $1.26 \%$ respectively. In addition, with the feed rate of $75 \mathrm{~mm} / \mathrm{min}$ and the five used tools, the ratios of increase in the (df) are; 1.21, 1.24, 1.28, 1.29 and $1.34 \%$ correspondingly. From the analysis of results, the delamination factor (df) is increased with the increase of the feed rate and with the increase of the point angle of the used tools between (VF, 15 and 25\%) with the same cutting speed $2500 \mathrm{rpm}$. The comparison between the results when used cutting speed $500 \mathrm{rpm}$, the five used tools and feed rate 15 $\mathrm{mm} / \mathrm{min}$ when (Vf) is changed from 15 to $25 \%$ with the same parameters when used cutting speed 2500 $\mathrm{rpm}$, the analysis indicated that, the increase in the volume fraction and the cutting speed are led to an increase in the delamination factors(df). The ratios of increase in (df) are; $1.24 \%$ with tool of point angle $\left(60^{\circ}\right)$ to $1.28,1.32,1.34$ and $1.36 \%$ for the other four tools $\left(70,80,90\right.$ and $\left.100^{\circ}\right)$. In addition, with feed rate $75 \mathrm{~mm} / \mathrm{min}$ and the same parameters, the ratios of increase in (df) are; 1.25, 1.32, 1.33, 1.36 and $1.42 \%$ for the used tools.

In Fig. (16), the relation between the feed rate (f) and the surface roughness $(\mathrm{Ra})$ with the same parameters, which used in the previous figure, is plotted. The increase in the feed rate leads to an increase in the surface roughness (Ra) of machined hole, and ( $\mathrm{Ra})$ increased with the increase of tool point angle. The ratios of increase in (Ra) with feed rate $15 \mathrm{~mm} / \mathrm{min}$ are from; $2.6 \%$ with tool of point angle $\left(70^{\circ}\right)$ to 2.9 , 3.6 and $4.1 \%$ for the others tools $\left(80,90\right.$ and $\left.100^{\circ}\right)$ respectively. With the other feed rates, it is changed to; $2.8,3.2,3.6$ and to $3.8 \%$ with tool of point angle $\left(60^{\circ}\right)$. For feed rate $30 \mathrm{~mm} / \mathrm{min}$, (Ra) increased from, $3.6 \%$ with tool point angle $\left(70^{\circ}\right)$ to $4.0,4.5$ and $4.9 \%$ for the other used tools. With feed rate $45 \mathrm{~mm} / \mathrm{min}$, the values of increase are changed to; 3.8, 4.2, 4.7and $5.1 \%$ for the four used tools. For the other used feed rates, 60 and $75 \mathrm{~mm} / \mathrm{min}$, the ratios of increase are; 3.9 and $4.5 \%$ with tool of $\left(70^{\circ}\right)$ and 4.1 and $4.9 \%$ with tool of $\left(80^{\circ}\right)$ point angle. For the tools of point angles (90 and $100^{\circ}$ ), the ratios of increase are; 4.5 and $5.0 \%$ and 4.7 and $5.4 \%$ for the same feed rates. It is obvious that, the change of volume fraction ratio to $25 \%$ with the same used parameters led to an increase in the values of $(\mathrm{Ra})$. In addition, the feed rate and the tool 
point angle are had a large effect in the resultant values of the surface roughness ( $\mathrm{Ra})$ at the used parameters. The increase of (Vf) from 15 to $25 \%$ leads to an increase in all values of the surface roughness (Ra) when used the same parameters with cutting speed $2500 \mathrm{rpm}$. The ratios of increase in (Ra) when use feed rate $15 \mathrm{~mm} / \mathrm{min}$ and with the used tools are; $1.07,1.08,1.09,1.11$ and $1.12 \%$. With feed rate of $75 \mathrm{~mm} / \mathrm{min}$ and the five used tools, the ratios of increase in (Ra) are changed to; 1.8, 1.09, 1.10, 1.16 and $1.22 \%$ respectively. From the analysis of the results and from this comparison, It is clear that, the values of ( $\mathrm{Ra})$ are increased with the increase of the feed rate and also with the increase of the point angle of the used tools between (VF,15 and 25\%) with the same cutting speed $2500 \mathrm{rpm}$. In the other side, the comparison between the results when used cutting speed $500 \mathrm{rpm}$, the used tools, feed rate $15 \mathrm{~mm} / \mathrm{min}$ and $(\mathrm{Vf}=25 \%)$ with the same parameters when used cutting speed $2500 \mathrm{rpm}$, the analysis indicated that, the increase in cutting speed leads to a decrease in the surface roughness $(\mathrm{Ra})$. The ratios of decrease in $(\mathrm{Ra})$ are; $0.63 \%$ with tool of point angle $\left(60^{\circ}\right)$ to; $0.66,0.68$, $0.70,0.74$ and $0.78 \%$ for the other used tools. With feed rate $75 \mathrm{~mm} / \mathrm{min}$ and the same parameters, the ratios of decrease in (Ra) are; 0.87, 0.91, 0.92, 0.96 and $0.97 \%$ for all used tools.

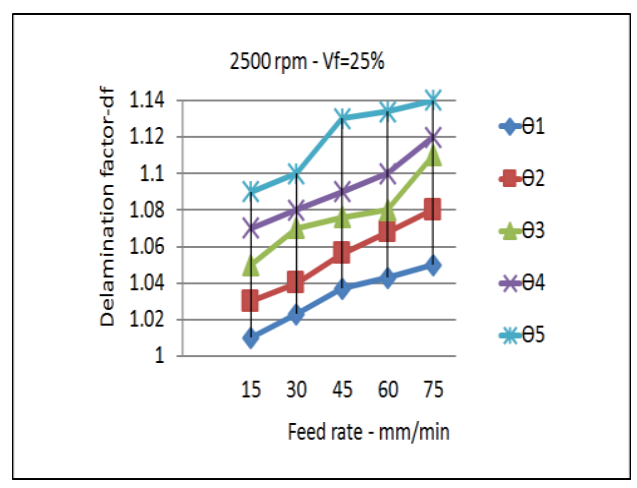

Figure 15: (df - f) Relation at; Vf $=25 \%$, RPM 2500 and five tools of different point angles.

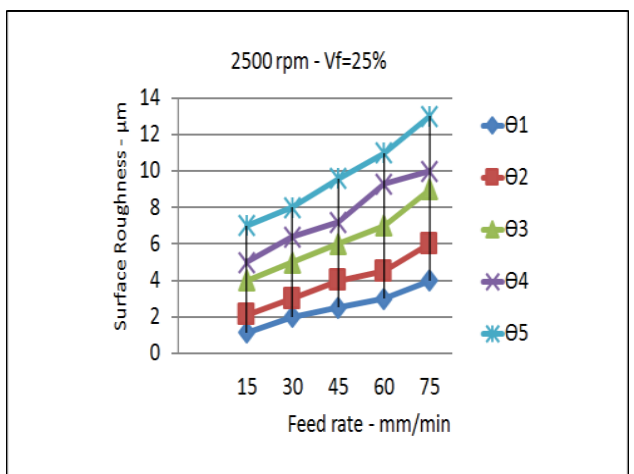

Figure 16: (Ra- f) Relation at; Vf $=25 \%, \mathrm{RPM} 2500$ and five tools of different point angles.

\subsubsection{RPM 2500 and Vf $35 \%$}

In Fig. (17), the same parameters, which used in the previous figure, but the volume fraction, changed from 25 to $35 \%$. (df) is increased with the increase of feed rate and increases with the increase of tool point angle. The average increase in (df) is between; 1.01 to 1.06 for the feed rates and with tool of point angle $\left(60^{\circ}\right)$ and is between 1.04 to 1.09 for the other used tools $\left(70,80,90\right.$ and $\left.100^{\circ}\right)$. With feed rates, 30, 45, 60 and $75 \mathrm{~mm} / \mathrm{min}$, the ratios of increase in (df) are, 0.56 , $0.68,0.78$ and $0.82 \%$ with tool of $\left(60^{\circ}\right)$ and $0.59,0.70$, 0.81 and $0.84 \%$ with tool of $\left(70^{\circ}\right)$ point angle. With the tool of point angle $\left(80^{\circ}\right)$, the ratios of increase in (df) are, $0.61,0.72,0.83$ and $0.86 \%$.When used the tools of point angles $\left(90\right.$ and $\left.100^{\circ}\right)$, the values are, 0.74 , $0.84,0.86$ and $0.88 \%$ and $0.75,0.82,0.88$ and to $0.91 \%$ for the same feed rates. According to the analysis of the results, the feed rate and tool point angle are the highly influential parameter, which influences the resultant values of $(\mathrm{df})$ at the used parameters. From the results also, the volume fraction ratio (Vf) had a large effect on the resultant values of (df) with the same cutting speed. The increase of (Vf) from 15 to $35 \%$ when used the same parameters with the cutting speed $2500 \mathrm{rpm}$ leads to an increase in all values of the delamination factor. The ratios of increase in (df) with feed rate $15 \mathrm{~mm} / \mathrm{min}$ and the five used tools are, $1.13,1.18,1.21,1.23$ and $1.25 \%$. In addition, with the feed rate of $75 \mathrm{~mm} / \mathrm{min}$ and the five used tools, the ratios of increase in (df) are, 1.17, 1.19, 1.23, 1.25 and to $1.28 \%$ respectively. The analysis of results indicated that, the delamination factor (df) is increased with the increase of feed rate and with the increase of point angle of the used tools between (VF, 
15 and 35\%) with the same cutting speed $2500 \mathrm{rpm}$. In the other side, the comparison between the results when used the cutting speed $500 \mathrm{rpm}$, the used tools , feed rate $15 \mathrm{~mm} / \mathrm{min}$ and the volume fraction ratio is changed to $35 \%$ with the same parameters when used cutting speed $2500 \mathrm{rpm}$, the analysis indicated that, the increase in cutting speed leads to an increase in (df) . The ratios of increase in (df) are; $1.13 \%$ with tool of point angle $\left(60^{\circ}\right)$ to; $1.15,1.16,1.17,1.21 \%$ for the other four tools $\left(70,80,90\right.$ and $\left.100^{\circ}\right)$. With feed rate $75 \mathrm{~mm} / \mathrm{min}$ and the same parameters, the ratios of increase in (df) are; 1.20, 1.25, 1.27, 1.30 and $1.45 \%$ for the uses tools.

From Fig. (18), the surface roughness ( $\mathrm{Ra}$ ) increased with the increase of feed rate and increases with the increase of tool point angle. The ratios of increase in (Ra) for feed rates, 30, 45, 60 and $75 \mathrm{~mm} / \mathrm{min}$ and with tool of point angle $\left(60^{\circ}\right)$, are, 3.0, 3.4, 3.8 and to $4.1 \%$. For feed rate $15 \mathrm{~mm} / \mathrm{min}$, (Ra) is increased from, $2.2 \%$ with tool of point angle $\left(70^{\circ}\right)$ to ,2.6, 3.2 and $3.6 \%$ for the others tools $\left(80,90\right.$ and $100^{\circ}$ ) respectively. When used feed rate $30 \mathrm{~mm} / \mathrm{min}$, (Ra) increased from; $3.8 \%$ with tool point angle $\left(70^{\circ}\right)$ to $4.2,5.4$ and $5.6 \%$ for the other used tools. When used feed rate $45 \mathrm{~mm} / \mathrm{min}$, the values are changed to; 3.9, $4.4,4.9$ and $5.7 \%$. The ratios of increase in (Ra) for the other feed rates 60 and $75 \mathrm{~mm} / \mathrm{min}$ are; 4.0 and $4.4 \%$ with tool of $\left(70^{\circ}\right)$ and with tool of $\left(80^{\circ}\right)$ point angle the values are changed to; 4.3 and $4.6 \%$. For the other two tools of point angles $\left(90\right.$ and $100^{\circ}$ ), the ratios of increase are; 4.4 and $5.7 \%$ and 4.5 and $5.9 \%$ for the same feed rates. The increase of volume fraction ratio from 25 to $35 \%$ with the same used parameters led to an increase in the values of (Ra). In addition, the feed rate and tool point angle are play a vital role in the resultant values of surface roughness (Ra) with the used parameters. The increase of (Vf) from 15 to $35 \%$ when used the same parameters with the cutting speed $2500 \mathrm{rpm}$ leads to an increase in all values of (Ra). The ratios of increase in (Ra) with feed rate $15 \mathrm{~mm} / \mathrm{min}$ and the used tools are; 1.03, 1.04, $1.07,1.10$ and $1.11 \%$. For feed rate of $75 \mathrm{~mm} / \mathrm{min}$ and the five used tools, the ratios of increase in (Ra) are changed to; 1.04, 1.05, 1.09, 1.13 and $1.15 \%$ respectively. From the analysis of the results, the values of the surface roughness ( $\mathrm{Ra}$ ) increased with the increase of feed rate and with the increase of the point angle of the used tool between (VF, 15 and 35\%) with the same cutting speed $2500 \mathrm{rpm}$. In the other side, the comparison between the results when used cutting speed $500 \mathrm{rpm}$, the used tools, feed rate 15 $\mathrm{mm} / \mathrm{min}$ and $(\mathrm{Vf}=35 \%)$ with the same parameters when used cutting speed $2500 \mathrm{rpm}$, the analysis indicated that, the increase in cutting speed leads to a decrease in the surface roughness (Ra). The ratios of decrease in (Ra) are; $0.61 \%$ with tool of point angle $\left(60^{\circ}\right)$ to; $0.63,0.68,0.70,0.75 \%$ for the other used tools. With feed rate $75 \mathrm{~mm} / \mathrm{min}$ and the same parameters, the ratios of decrease in (Ra) are; 0.80, $0.85,0.92,0.96$ and $0.98 \%$ for all used tools.

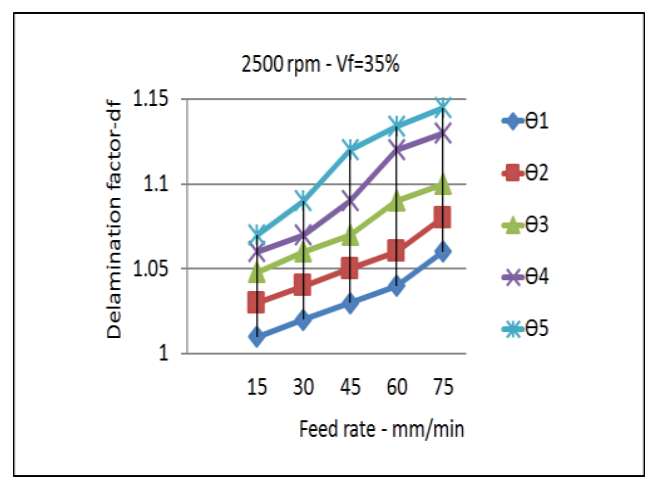

Figure 17: (df - f) Relation at; Vf =35\%, RPM 2500 and five tools of different point angles.

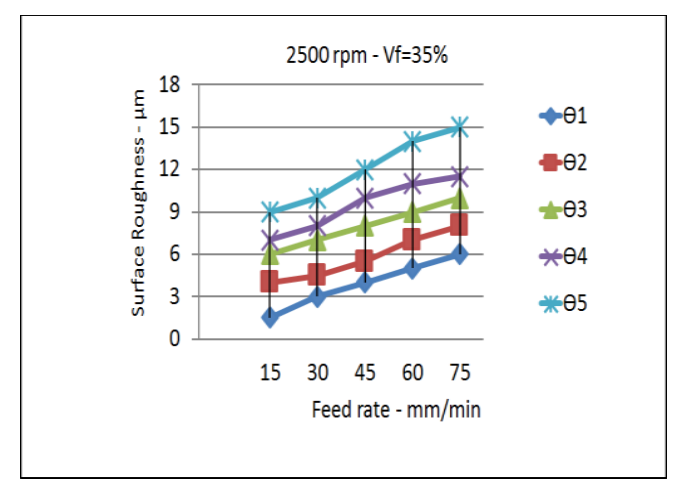

Figure 18: (Ra - f) Relation at; Vf $=35 \%$, RPM 2500 and five tools of different point angles.

\section{Conclusions}

This research presented the experimental methodology which applied to study the influence of drilling parameters; the feed rate, the tool geometry , the cutting speed, and the volume fraction ratio on the process responses, i.e. the delamination (df) and the surface roughness $(\mathrm{Ra})$ of the drilled hole in $\mathrm{AL} / \mathrm{SiCp}$ metal matrix composite MMC. From the 
deeply analysis of the results, it can be concluded that:

1) The feed rate and the point angle of the tool are had a large influence on delamination factor (df) and surface roughness (Ra), while both of the delamination and the surface roughness are increased with the increase in the feed rate from 15 to 75 $\mathrm{mm} / \mathrm{min}$ and the point angle from $60^{\circ}$ to $100^{\circ}$.

2) A clear increase in the values of the delamination factor (df) when the cutting speed is increased to 2500 $\mathrm{rpm}$ and feed rate $75 \mathrm{~mm} / \mathrm{min}$ combined with the tool of point angle $\left(100^{\circ}\right)$.

3) The delamination factor (df) and the surface roughness $(\mathrm{Ra})$ are increased with the increase of volume fraction ratios.

4) The increase of volume fraction ratio is led to an evident increase in the delamination factor (df) with all values of; the feed rates, the tool of point angles and the cutting speeds.

5) The increase of volume fraction ratio led to a clear increase in the surface roughness ( $\mathrm{Ra})$ with all values of, the feed rates and the point angle of tools.

6) The analysis of the results demonstrated a good association between the results of the delamination factor (df) and the surface roughness (Ra) with the point angle of the used tools.

7) The values of the delamination factor (df) are increased with the increase of the tool point angle with all values of, the feed rates, the cutting speeds and volume fraction ratios.

8) The surface roughness ( $\mathrm{Ra}$ ) values increased with the increase in all values of, the feed rates, the tool point angle and the volume fraction ratios.

9) The values of the delamination factor ( $\mathrm{df}$ ) are decreased with the feed rate $(15 \mathrm{~mm} / \mathrm{min})$, the tool of point angle $\left(60^{\circ}\right)$ and the cutting speed (500

rpm) combined with the volume fraction ratio $15 \%$.

10) The values of the surface roughness (Ra) decreased with the feed rate $(15 \mathrm{~mm} / \mathrm{min})$, the tool of point angle $\left(60^{\circ}\right)$ and the cutting speed $(2500 \mathrm{rpm})$ combined with the volume fraction ratio $15 \%$.

\section{References}

1. S. Senthil Babu, B. K. Vinayagam, Modeling and analysis of surface roughness and thrust force in drilling of Al based Metal Matrix / Hybrid Composites, Int. Review on Modelling and Simulations (IREMOS), Vol. 8, No.4, (2015).

2. S. T. Huang, L. Zhou, J. Chen, L. F. Xu, Drilling of $\mathrm{SiCp} / \mathrm{Al}$ Metal Matrix Composites with Polycrystalline Diamond (PCD) tools, Materials and Manufacturing Processes, Vol.27, 2012-Issue 10.

3. A. Taskesen, K. Kutukde, Analysis and optimization of drilling parameters for tool wear and hole dimensional accuracy in B4C reinforced Al-alloy, Trans. Nonferrous Met. Soc. China 23(2013), 2524-2536.

4. Vikas K Doomra, Kishore Debnath, Inderdeep Singh, Drilling of Metal Matrix Composites: Experimental and finite element analysis, Proc IMechE Part B: J Engineering Manufacture, 1-5, IMechE 2014.

5. Sarbjit Singh, Effect of modified drill point geometry on drilling quality characteristics of metal matrix composite (MMCs), J. Of Mechanical Science and Technology, 30 (6) (2016), 2691-2698.

6. A. Muniaraj, Sushil Lal Das, K. Palanikumar, Evaluation of thrust force and surface roughness in drilling of $\mathrm{Al} / \mathrm{Sic} / \mathrm{Gr}$ Hybrid Metal Matrix Composite, Inter. J. of Latest Res. in Sci. and Tech., Vol.2,Issue 4,48,(2013).

7. Srinivasan, A., R.M. Arunachalam, S. Ramesh, S. Senthilkumar, Machining performance study on Metal Matrix Composites-A Response Surface Methodology Approach, American J. of Applied Sci., 9 (4), 478-483, 2012.

8. R.Venkatesh A, A.M.HariharanB, N.MuthukrishnanC, Machinability Studies of Al/Sic/ (20p) MMC by using PCD insert (1300 grade), Proceedings of the World Congress on Engineering, Vol. II, WCE 2009, July 1 3, 2009, London, U.K.

9. A. Muniaraj, Sushil Lal Das, b, K. Palanikumarr, Influence of drilling parameters on thrust force in drilling of Sic and graphite reinforced aluminum matrix composites by step drill, Proceedings of the National Conference on Trends and Advances in Mechanical Engineering, YMCA University of Science \& Technology, Faridabad, Haryana, Oct 19-20, 2012.

10. Vijaykumar Hiremath, Pradeep Badiger, V Auradi, S T Dundur; S A Kori, Influence of particle size on cutting forces and surface roughness in machining of B4Cp - 6061 Aluminum Matrix Composites, IOP Conf. Series: Materials Science and Engineering, 114 (2016).

11. Sarbjit Singh, Abhishek Singh, Inderdeep Singh, Akshay Dvivedi, Optimization of the Process Parameters for drilling of Metal Matrix Composites (MMC) Using Taguchi Analysis. Adv. Mat. Res., Vol. 410 (2012), 249-252. 
12.V M Ravindranath, G S Shiva Shankar, S Basavarajappa, R Suresh, Effect of cutting parameters on thrust force and surface roughness in drilling of $\mathrm{Al}-$ 2219/B4C/Gr Metal Matrix Composites ,IOP Conf. Series: Materials Science and Engineering ,149 (2016).

13.T. Rajmohan, K. Palanikumar, Modeling and analysis of performances in drilling hybrid metal matrix composites using D-optimal design, Int J Adv. Manuf. Technol. (2013) 64, 1249-1261.

14.Hari Singh, Abhishek Kamboj, Sudhir Kumar, Multi Response Optimization in drilling Al6063/Sic/15\% Metal Matrix Composite, Int. J. of Chemical, Molecular, Nuclear, Materials and Metallurgical Engineering, Vol. 8, No. 4, 2014.
15.Ahmad Mayyas, Awni Qasaimeh, Khalid Alzoubi, Susan Lu, Mohammed T. Hayajneh , Adel M. Hassan, Modeling the drilling process of Aluminum Composites Using Multiple Regression Analysis and Artificial Neural Networks ,J. of Minerals and Materials Characterization and Engineering, 2012, Vol.11, 10391049. 